CLINICAL STUDY

\title{
Endothelial nitric oxide synthase intron $4 a / b$ polymorphism and early atherosclerotic changes in hypopituitary GH-deficient adult patients
}

\author{
Fatma Sen ${ }^{1}$, Mustafa Demirturk ${ }^{1}$, Neslihan Abaci ${ }^{2}$, Ebru Golcuk $^{3}$, Huseyin Oflaz ${ }^{3}$, Ali Elitok ${ }^{3}$, Faruk Kutluturk, \\ Halim Issever ${ }^{4}$, Nihan Erginel Unaltuna ${ }^{2}$ and Nese Colak Ozbey \\ Division of Endocrinology, Department of Medicine, Istanbul Faculty of Medicine, Istanbul University, 34390 Capa, Istanbul, Turkey, ${ }^{1}$ Department of \\ Medicine, Istanbul Faculty of Medicine, ${ }^{2}$ Department of Genetics, Institute for Experimental Medical Research, Istanbul University, 34390 Istanbul, \\ Turkey, Departments of ${ }^{3}$ Cardiology and ${ }^{4}$ Public Health, Istanbul Faculty of Medicine, Istanbul University, 34390 Istanbul, Turkey \\ (Correspondence should be addressed to N C Ozbey; Email: nozbey@hotmail.com)
}

\begin{abstract}
Objective: Endothelial nitric oxide synthase (eNOS) intron $4 \mathrm{a} / \mathrm{b}$ polymorphism is associated with plasma NO concentrations and coronary artery disease/hypertension in various populations. GH deficiency in adulthood predisposes to reduced NO concentrations and premature atherosclerosis. Our aim was to determine whether intron $4 \mathrm{a} / \mathrm{b}$ polymorphism of eNOS gene influences endothelial function and early atherosclerotic changes in GH-deficient hypopituitary patients.

Design: Thirty-three hypopituitary GH-deficient patients on conventional replacement therapy other than GH and 43 age-, sex-, and body mass index (BMI)-matched controls were studied in this crosssectional case-control study.

Methods: Early atherosclerotic changes were determined by flow-mediated dilation (FMD) of brachial artery and carotid artery intima-media thickness (IMT). eNOS4a/b polymorphism was detected by PCR. Results: Hypopituitary patients had significantly higher total/low-density lipoprotein cholesterol and fat mass and lower IGF-I concentrations compared with controls. IMT was significantly higher in patients $(0.777 \pm 0.23$ vs $0.639 \pm 0.17 \mathrm{~mm}, P<0.01)$. No significant difference was observed with respect to FMD measurements. eNOS4a/b genotype frequencies were similar between patients and controls. Patients carrying ' $a$ ' allele $(a / a$ and $a / b)$ had significantly higher IMT compared with controls carrying 'a' allele and bb genotype $(P<0.05)$. However, logistic regression analysis revealed that presence of hypopituitarism, age $\geq 45$ years, and $\mathrm{BMI} \geq 27.9 \mathrm{~kg} / \mathrm{m}^{2}$ were significant independent predictors of $\mathrm{IMT} \geq 0.65 \mathrm{~mm}$.

Conclusion: No compelling data are evident to suggest that eNOS4a/b polymorphism modifies the atherosclerotic process in GH-deficient situations. A large case-control study is needed to confirm our findings.
\end{abstract}

European Journal of Endocrinology 158 615-622

\section{Introduction}

Long-standing growth hormone (GH) deficiency in adulthood may predispose to the development of premature atherosclerosis (1-4). Epidemiological evidence indicated an increased incidence of cardiovascular and cerebrovascular diseases in hypopituitary patients treated with conventional replacement therapy other than $\mathrm{GH}$ $(1,3,4)$. A causal relationship is suggested between $\mathrm{GH}$ deficiency and increased vascular mortality and morbidity $(1,3,5)$. Several studies indicated improved atherosclerotic risk profile and vascular reactivity after GH replacement therapy in hypopituitary patients (6-9).

The endothelium modulates vascular tone by producing vasodilator and vasoconstrictor substances. Nitric oxide (NO) produced by endothelial cells modulates vascular tone and confers protection against atherosclerosis
$(10,11)$. Endothelial dysfunction that results in reduced availability of NO is recently identified as an early marker of atherosclerosis and has value to predict future coronary artery disease before anatomical evidence of atherosclerosis appears $(10,11)$. Flow-mediated dilation (FMD) defined as a change in arterial diameter in response to reactive hyperemia is an endothelium-dependent process. Flowmediated endothelium-dependent dilation evaluated noninvasively by ultrasonography has been used to determine endothelial function in medium-sized vessels and brachial artery measurements can be used as a surrogate marker for coronary endothelial function (12-14).

The endothelial cells produce NO by the enzyme NO synthase (eNOS) $(10,11)$. Decreased production of NO by eNOS may contribute to the endothelial dysfunction and early atherosclerotic changes. Previous studies indicated that polymorphisms of eNOS gene could lead to decreased 
NO availability and play a role for the development of atherosclerotic cardiovascular disease $(15,16)$. A significant association between variable number of tandem repeat (VNTR) polymorphism in intron 4 of eNOS gene (eNOS4a/b polymorphism) and coronary artery disease/ hypertension has been detected in various populations (17-19), although this association has not been confirmed in some studies (20-22). In addition, eNOS4a/b polymorphism has been reported to be associated with decreased plasma NO concentrations (15).

In a GH-deficient patient, endothelial NO production by eNOS may further diminish. Boger et al. (23) indicated decreased NO formation in untreated GH-deficient patient, which has been reversed after GH replacement therapy. Insulin-like growth factor-I (IGF-I) has been reported to directly simulate NO production in endothelial cells as a result of the activation of eNOS possibly by a tyrosine kinase-dependent mechanism (24).

Thickening of the intima and tunica media of the arteries is another marker of initial asymptomatic atherosclerosis. The increase in intima-media thickness (IMT) in the extracranial carotid arteries is reported to be associated with a higher prevalence of coronary heart disease and described as a surrogate marker of coronary atherosclerosis $(25,26)$.

The aim of this study is to determine whether the intron $4 \mathrm{a} / \mathrm{b}$ polymorphism of eNOS gene modulates endothelial function and early atherosclerotic changes in GH-deficient hypopituitary patients compared with controls.

\section{Materials and methods}

\section{Patients and controls}

Thirty-three hypopituitary patients with at least three pituitary hormone deficits (adrenocorticotrophin; ACTH, thyrotrophin; TSH, and gonadotrophins) other than $\mathrm{GH}$ (12 males and 21 females) and forty-three healthy controls (17 males and 26 females) were studied.

Subjects affected by diabetes mellitus, hypertension or any other established cardiovascular disease, and other chronic diseases that could affect endothelial function were excluded.

The patients and controls were matched for age, sex, and body mass index (BMI; Table 1). Patients were recruited from the Endocrinology Clinic of Internal Medicine at Istanbul Faculty of Medicine. Controls were recruited from hospital staff and friends. The study was performed according to the Declaration of Helsinki and Institutional Ethical Committee approved the study. Written informed consent was obtained from all study participants (both patients and controls).

Causes of hypopituitarism were tumors of sellar and suprasellar region (macroprolactinomas in 3 cases, craniopharyngiomas in 3 cases, germinomas in 2 cases, hypothalamic glioma in 1 case, GH-secreting pituitary adenoma in 1 case, ACTH-secreting pituitary adenoma in 1 case, and non-functional lesions in 7 cases) treated by surgery, radiotherapy, or both in 18 patients, Sheehan's syndrome in 7 patients, primary empty sella in 2 patients, septo-optic dysplasia in 5 patients, and Langerhans cell granulomatosis of hypothalamic-pituitary region in 1 patient. The patient with a diagnosis of GH-secreting pituitary adenoma was operated transsphenoidally 17 years before. The patient with a diagnosis of ACTH-secreting pituitary adenoma was operated transsphenoidally 12 years before. In both of these patients, panhypopituitarism developed after the operation. Mean duration of hypopituitarism was $123.06 \pm 101.97$ months (median: 132.00 months, range: $12-360$ months). All patients were on conventional replacement therapy consisting of L-thyroxine, glucocorticoids, sex hormones (except for

Table 1 Study parameters in patients and controls.

\begin{tabular}{|c|c|c|c|}
\hline & Patients $n: \mathbf{3 3}$ & Controls $n: 43$ & $\boldsymbol{P}$ \\
\hline Gender (male/female) ${ }^{\mathrm{a}}$ & $12 / 21$ & $17 / 26$ & NS \\
\hline Age (years) & $44.09 \pm 16.71$ & $43.76 \pm 13.36$ & NS \\
\hline Systolic $\mathrm{BP}^{\mathrm{b}} \mathrm{mmHg}$ & $117.72 \pm 18.33$ & $119.32 \pm 16.24$ & NS \\
\hline Diastolic $\mathrm{BP}^{\mathrm{b}} \mathrm{mmHg}$ & $76.06 \pm 12.23$ & $76.39 \pm 10.06$ & NS \\
\hline Glucose $\mathrm{mmol} / \mathrm{l}$ & $4.50 \pm 0.92$ & $4.64 \pm 0.77$ & NS \\
\hline Cholesterol mmol/l & $5.47 \pm 0.91$ & $4.82 \pm 1.02$ & 0.005 \\
\hline Triglycerides ${ }^{\mathrm{b}} \mathrm{mmol} / \mathrm{l}$ & $1.56 \pm 0.84$ & $1.53 \pm 1.16$ & NS \\
\hline HDL cholesterol $\mathrm{mmol} / \mathrm{l}$ & $1.30 \pm 0.32$ & $1.25 \pm 0.32$ & NS \\
\hline LDL cholesterol mmol/l & $3.38 \pm 0.82$ & $2.91 \pm 0.82$ & 0.015 \\
\hline Free $\mathrm{T}_{4} \mathrm{pmol} / \mathrm{l}$ & $15.10 \pm 3.69$ & $14.01 \pm 1.93$ & NS \\
\hline IGF-I $\mu \mathrm{g} / \mathrm{I}$ & $59.85 \pm 31.01$ & $150.99 \pm 42.01$ & $<0.001$ \\
\hline $\mathrm{BMI} \mathrm{kg} / \mathrm{m}^{2}$ & $28.65 \pm 5.88$ & $27.27 \pm 5.11$ & NS \\
\hline Fat mass (\%) & $43.28 \pm 11.33$ & $37.44 \pm 11.56$ & 0.032 \\
\hline WHR & $0.883 \pm 0.07$ & $0.868 \pm 0.10$ & NS \\
\hline FMD (\%) & $5.88 \pm 3.53$ & $7.29 \pm 4.57$ & NS \\
\hline IMT (mm) & $0.777 \pm 0.23$ & $0.639 \pm 0.17$ & 0.007 \\
\hline
\end{tabular}

BP, blood pressure; BMI, body mass index; WHR, waist-to-hip ratio; FMD, flow-mediated dilation; IMT, carotid artery intima-media thickness; IGF-I, insulin-like growth factor-I; NS, not significant.

Values are mean \pm s.D. Statistical significance was determined by Student's unpaired $t$-test and ${ }^{\mathrm{a}}\left(\chi^{2}\right.$ test $)$.

${ }^{\mathrm{b}}$ For comparison log transformed values were used. 
postmenopausal women), and desmopressin where necessary. Out of 21 and 26 women in hypopituitary and control groups, 10 were postmenopausal in each group respectively $(P>0.05)$. In the control group, the postmenopausal women were not receiving sex hormone preparation and the premenopausal women had regular menstrual cycles. None of the patients received $\mathrm{GH}$ replacement therapy for at least 12 months before the study. All patients were stable on conventional replacement treatment for at least 6 months before the study. Replacement doses had been optimized previously for the individual patients on the basis of clinical and biochemical evaluation and target hormone concentrations. This regimen was continued in the present study. Biochemical markers of thyroid, liver, and kidney functions were within normal range in all subjects. Only 2 out of 33 hypopituitary patients and 5 out of 43 controls had positive family history of coronary heart disease $(P>0.05)$.

Subjects were classified as those who had never smoked, ex-smoker, and current smokers. Number of the patients in these subgroups were as follows: patient group, 26/33, 1/33, and 6/33 respectively; control group, $30 / 43,3 / 43$, and $10 / 43$ respectively $(P>0.05)$.

$\mathrm{GH}$ deficiency was determined according to the following criteria: at least three pituitary hormone deficiencies together with 1) IGF-I concentrations lower than mean-2 S.D. of the control group $(<67 \mu \mathrm{g} / \mathrm{l})$ $(27,28)$ and/or 2) maximum stimulated serum $\mathrm{GH}$ concentrations lower than $3 \mu \mathrm{g} / \mathrm{l}$ in response to previously administered glucagon (29). All patients were $\mathrm{GH}$ deficient according to these criteria.

\section{Study protocol}

Patients and controls attended the Endocrinology Clinic of Internal Medicine Department after an overnight fast of $12 \mathrm{~h}$. The investigation was carried out on an outpatient basis. Menstruating women (patients and controls) were studied during the early follicular phase of menstrual cycle. Venous blood was obtained for genotype determination and measurements of glucose, triglycerides, total cholesterol, high-density lipoprotein (HDL) cholesterol, low-density lipoprotein (LDL) cholesterol, routine hematological, liver, renal function tests, free thyroxine $\left(\mathrm{T}_{4}\right)$, and IGF-I concentrations. Samples were stored at $-70{ }^{\circ} \mathrm{C}$ until eNOS $4 \mathrm{a} / \mathrm{b}$ polymorphism analysis; all other parameters were determined on the same day of collection. After blood sampling, anthropometric measurements were performed. Body composition was determined by bioimpedance analysis. FMD of brachial artery and carotid artery IMT measurements were performed on the same day after anthropometric measurements were taken.

\section{Anthropometric and physical parameters}

BMI was calculated as the ratio of weight $(\mathrm{kg})$ divided by the square of height $\left(\mathrm{m}^{2}\right)$. Waist-to-hip ratio (WHR) was calculated as waist circumference $(\mathrm{cm})$ divided by hip circumference $(\mathrm{cm})$.

Body composition was measured by a bioelectrical impedance analyser (Bodystat 1500, Bodystat Ltd, Douglas, Isle of Man, British Isles, Great Britain) after overnight fast with an empty bladder in the morning of the anthropometric measurements and blood samples were taken.

Systolic and diastolic blood pressures were measured on the right arm of the subject in an upright sitting position after at least $5 \mathrm{~min}$ rest using a mercury sphygmomanometer with appropriate cuff size.

\section{Metabolic and hormone parameters}

All biochemical analyses including glucose, total cholesterol, HDL cholesterol, LDL cholesterol, and triglyceride concentrations were performed at Roche/Hitachi Modular Analytics System in the Central Biochemistry Laboratory. Glucose was measured by an oxidase-based technique. LDL and HDL cholesterol were determined by direct method (homogeneous enzymatic assay for the direct quantitative determination of LDL and HDL cholesterols) at Roche/Hitachi Modular Analytics System.

Free $\mathrm{T}_{4}$ concentrations were analyzed at this system by electrochemiluminescence immunoassay (ECLIA; E170 Module, Tokyo, Japan).

Serum IGF-I concentrations were measured on an Immulite and Immulite 1000 Analyzer using an enzyme-labeled chemiluminescent immunometric assay (EURO/DPC Ltd, Gwynedd, UK).

\section{Measurement of endothelial function}

Brachial artery FMD (endothelium dependent process) was performed as previously reported by an ultrasonic vessel wall-tracking system $(10 \mathrm{MHz}$ linear transducer attached to standard Vingmed System Five, Horten, Norway) (12). The brachial artery of the dominant arm was identified and a two-dimensional longitudinal B-mode image of the brachial artery was obtained. The brachial artery internal diameter was assessed at end diastole (timed by the QRS complex) and arterial flow volume was measured using the pulse Doppler sample volume at $\leq 70^{\circ}$ angle in the center of the artery. Forearm ischemia was caused by inflating a pneumatic arm cuff up to $200 \mathrm{mmHg}$ for $5 \mathrm{~min}$. The cuff was deflated and the arterial flow volume was immediately recorded. Arterial diameter was measured at $60 \mathrm{~s}$ after deflation. Three consecutive measurements were taken before inflation and after deflation. Mean of these three measurements was used for calculation: ((mean arterial diameter $60 \mathrm{~s}$ after deflation $)-($ mean baseline diameter $) /($ mean baseline diameter $) \times 100$.

Results were expressed as percentage changes from baseline. Subjects did not smoke or drink caffeine rich 
beverages for $12 \mathrm{~h}$ before testing. Intra-observer variability of FMD measurement was 3.3\%.

\section{Ultrasound measurement of the common carotid artery}

Bilateral carotid ultrasound was carried out using an ultrasound system with a high-resolution $10 \mathrm{MHz}$ linear array scan head (attached to standard Vingmed System Five). The common carotid arteries were scanned longitudinally. The bulb dilation served as a landmark to indicate the border between distal common carotid artery and the carotid bulb. Images were obtained from the distal portion of the common carotid artery, $1-2 \mathrm{~cm}$ proximal to the carotid bulb. Images were saved and stored on S-VHS videotape. The two bright echogenic lines in the arterial wall were identified as the intima and media lines. The first echogenic line represents the lumen-intima interface and the second echogenic line represents the media-adventitia interface. The intimal plus medial thickness was measured as the distance from the main edge of the first to main edge of the second echogenic line. Each measurement was repeated thrice, and the mean of the left and right common carotid arteries was taken and used for further analysis. None of the subjects had atheromatous plaque, localized lesion of thickness $>2.0 \mathrm{~mm}$, or stenosis in this region. Intra-observer variability of IMT measurement was $3.6 \%$.

\section{Genetic polymorphism analysis}

eNOS intron $4 \mathrm{a} / \mathrm{b}$ polymorphism was determined by PCR using oligonucleotide primers (sense: $5^{\prime}$-AGGCCCTATGGTAGTGCCTTT- ${ }^{\prime}$; antisense: $5^{\prime}$-TCTCTTAGTGCTGTGGTCAC-3') that flank the region of the $27 \mathrm{bp}$ VNTR in intron 4 . Reactions were performed in a total volume of $50 \mu \mathrm{l}$ containing $100 \mathrm{ng}$ genomic DNA, 10 pmol of each primer, $0.2 \mathrm{mM}$ dNTP, $1 \mathrm{U}$ Taq DNA polymerase, $5 \mu \mathrm{l}$ PCR buffer $(500 \mathrm{mmol} / \mathrm{l} \mathrm{KCL}$, $100 \mathrm{mmol}$ 3-hydroxy-methyl-aminomethane chloride and $0.8 \%$ Nonidet $\mathrm{P} 40$ ). The thermocycling procedure consisted of initial denaturation at $94^{\circ} \mathrm{C}$ for $1 \mathrm{~min}$, annealing at $58{ }^{\circ} \mathrm{C}$ for $1 \mathrm{~min}$, and extension at $72{ }^{\circ} \mathrm{C}$ for $1 \mathrm{~min}$. The PCR products were analyzed using 3\% agarose gel electrophoresis $90 \mathrm{~V}$ for $1 \mathrm{~h}$ and visualized by ethidium bromide staining. The large allele eNOS4b contains five tandem $27 \mathrm{bp}$ repeats, and smaller allele eNOS4a contains four repeats. The sizes of PCR products were 393 and $420 \mathrm{bp}$ for eNOS4a and eNOs $4 \mathrm{~b}$ alleles respectively.

\section{Statistical analysis}

All statistical analyses were performed with SPSS V. 11.0 (SPSS, Illinois, US). Descriptive statistical results are presented in the tables as the mean \pm s.D.
The frequencies of the genotype distribution (4a/a, $4 \mathrm{a} / \mathrm{b}$, and $4 \mathrm{~b} / \mathrm{b}$ ) were compared between patients and controls by $\chi^{2}$ test. Distribution of genotypes within groups was in accordance with the distribution predicted by the Hardy-Weinberg equilibrium model. Continuous variables among the genotypes were compared with the use of ANOVA and a post hoc Tukey test. Independent sample $t$-test was used to compare continuous variables between patients and controls. Categorical data were compared by $\chi^{2}$ and Fisher's exact test where appropriate. The triglyceride and systolic and diastolic blood pressure measurements significantly deviated from a normal distribution by Kolmogorov-Smirnov test. Therefore, log-transformed values were used for these parameters. Univariate and logistic regression analyses were used to evaluate the significant associations between study parameters and genotypes. All tests were two sided and a $P$ value $<0.05$ was considered as significant.

\section{Results}

Baseline characteristics of patients and controls were summarized in Table 1.

Hypopituitary GH-deficient patients had significantly higher total and LDL cholesterol and lower IGF-I concentrations compared with controls. Percent fat mass determined by bioelectrical impedance analysis was significantly higher in patients. Lower FMD measurements were observed in patients, although difference did not reach statistical significance. IMT of common carotid arteries was significantly higher in patients compared with controls.

\section{Genotype frequencies}

The distribution of eNOS $4 \mathrm{a} / \mathrm{b}$ genotype frequencies were shown in Table 2. The genotype frequencies were in agreement with Hardy-Weinberg equilibrium. Frequencies were not significantly different between patients and controls $\left(\chi^{2}: 3.21, P=0.20\right)$.

Baseline characteristics were compared among genotype $(a / a, a / b$, and $b / b)$ carriers in the whole group and in the patients. None of the subjects carried the a/a genotype in the control group. No significant difference was observed with respect to baseline characteristics

Table 2 Endothelial nitric oxide synthase (eNOS) 4a/b genotype distribution in hypopituitary growth hormone (GH)-deficient patients and controls.

\begin{tabular}{lcc}
\hline eNOS4a/b & Patients $\boldsymbol{n}: \mathbf{3 3}$ & Controls $\boldsymbol{n}: \mathbf{4 3}$ \\
\hline a/a $n(\%)$ & $2(6.1)$ & - \\
a/b $n(\%)$ & $9(27.3)$ & $16(37.2)$ \\
b/b $n(\%)$ & $22(66.6)$ & $27(62.8)$ \\
Total $n(\%)$ & $33(100)$ & $43(100)$ \\
$\chi^{2}: 3.21, P=0.20$ & & \\
\hline
\end{tabular}


among three genotypes in the patients and the whole group (data not shown). The patients and controls were further grouped into genotype carriers containing ' $a$ ' allele $(a / a$ and $a / b)$ and $b / b$. No significant difference was observed in terms of study parameters between controls carrying ' $a$ ' allele and b/b genotype (data not shown). In the patient group, diastolic blood pressure was the only significantly different parameter between patients carrying ' $a$ ' allele $(\mathrm{a} / \mathrm{a}$ and $\mathrm{a} / \mathrm{b})$ and $\mathrm{b} / \mathrm{b}$ genotype; being significantly higher in patients carrying eNOS 'a' allele (a/a and $a / b)$ compared with patients carrying $\mathrm{b} / \mathrm{b}$ genotype $(82.72 \pm 11.90 \mathrm{mmHg}$ versus $72.72 \pm 11.20 \mathrm{mmHg}$ respectively, $P=0.029)$.

Patients carrying ' $a$ ' allele $(a / a$ and $a / b)$ and $b / b$ genotype and controls carrying ' $a$ ' allele $(a / a$ and $a / b)$ and $b / b$ genotype were compared (Table 3 ). IMT was significantly higher in patients carrying ' $\mathrm{a}$ ' allele compared with controls carrying ' $a$ ' allele and $b / b$ genotype. Although patients carrying $b / b$ genotype had significantly higher cholesterol concentrations, IMT was not significantly different between patients carrying $\mathrm{b} / \mathrm{b}$ genotype and controls. No significant difference was observed with respect to FMD measurements between patients and controls carrying 'a' allele or b/b genotype.

\section{Correlations between FMD/IMT and study parameters}

In the patients, IMT was significantly correlated with age, BMI, diastolic, and systolic blood pressure. No significant association between FMD and study parameters was observed in hypopituitary patients. In the controls, IMT correlated significantly with age, BMI, WHR, and glucose. No significant association was observed between FMD and study parameters in the controls either (Table 4). Significant univariate relationships were further evaluated in a multivariate logistic regression analysis model including genotypes. Patients and controls carrying ' $a$ ' allele $(a / a$ or $a / b)$ were labeled as (1) and bb genotype was labeled as (0) for this analysis. For continuous parameters (age, BMI, systolic and diastolic blood pressure, WHR, and glucose), median values of the parameters in the whole group were chosen as limits. Patients and controls having values greater than these limits were labeled as (1) and values less than these limits were labeled as (0). Presence of hypopituitarism (regression coefficient $=$ 1.622, $P=0.006$ ), BMI $>27.9 \mathrm{~kg} / \mathrm{m}^{2}$ (regression coefficient $=1.669, P=0.004$ ), and age $\geq 45$ years (regression coefficient $=1.326, P=0.019$ ) had significantly and independently predicted study subjects with an IMT $\geq 0.65 \mathrm{~mm}$. Carrying an ' $\mathrm{a}$ ' allele did not significantly enter in this regression model. The ratio for accurately classifying the study subjects with an IMT $\geq 0.65 \mathrm{~mm}$ according to this model was $72.4 \%$.

\section{Discussion}

In this study, although BMI-, age-, and sex-matched controls were used, percent fat mass, total, and LDL cholesterol concentrations were significantly higher in the patients compared with controls. Our findings supported previous observations indicating increased fat mass and a more atherogenic lipid profile in GH-deficient adults $(6,8,9,30)$. Carotid artery IMT was significantly higher in our patients compared with controls $(0.777 \pm 0.23 \mathrm{~mm}$ versus $0.639 \pm 0.17 \mathrm{~mm}$, $P<0.01)$. Increased IMT, intimal plaque formation, and reduced arterial compliance were reported previously in

Table 3 Baseline characteristics of hypopituitary patients and controls carrying 'a' allele (genotypes a/a and a/b) and bb genotype.

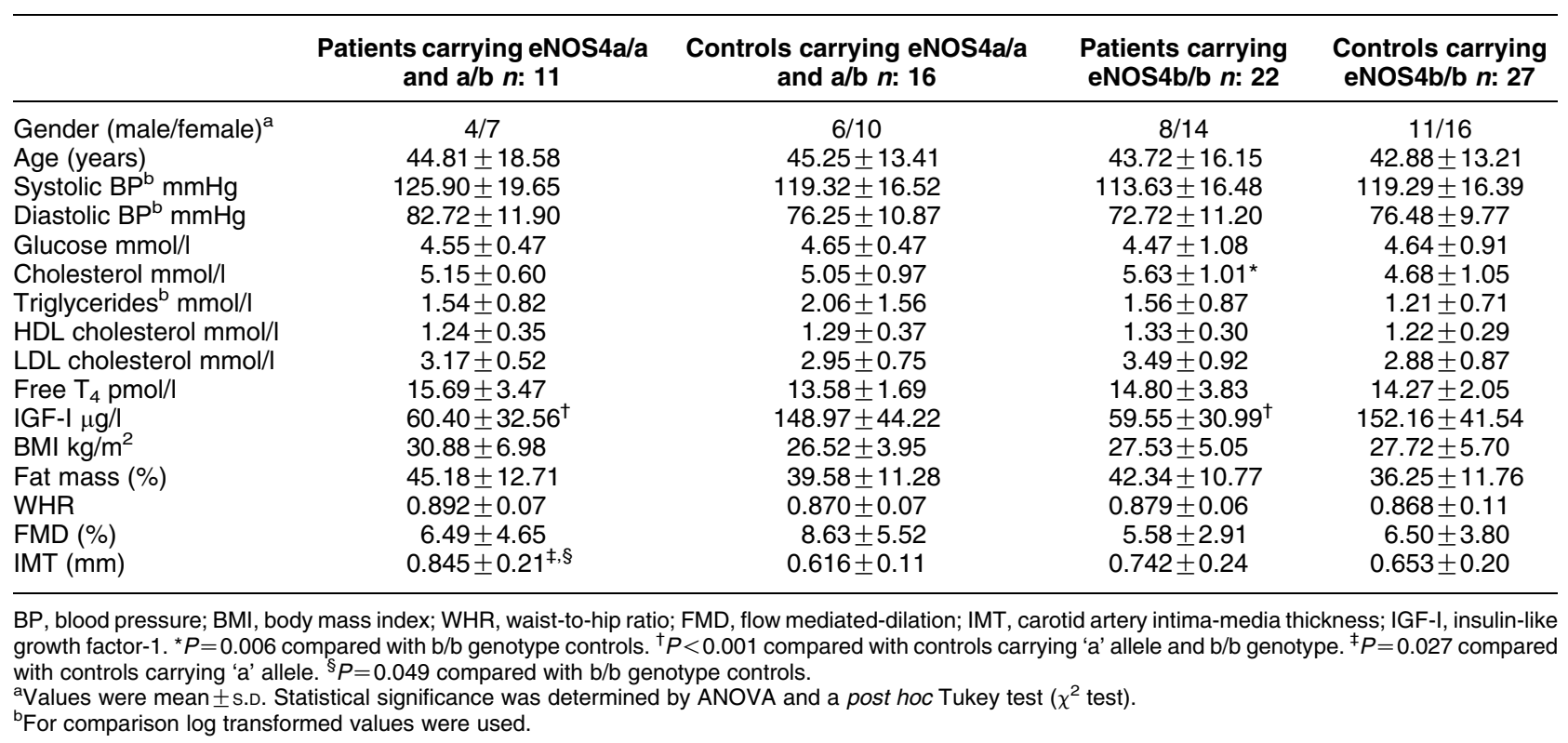


Table 4 Significant univariate associations between intima-media thickness (IMT) and study parameters in patients and controls.

\begin{tabular}{llc}
\hline & Patients & Controls \\
\hline IMT & & \\
& Age & Age \\
$r=0.511$ & $r=0.332$ \\
$P=0.002$ & $P=0.03$ \\
BMl & BMl \\
$r=0.429$ & $r=0.441$ \\
$P=0.002$ & $P=0.003$ \\
Systolic BP & WHR \\
$r=0.435$ & $r=0.545$ \\
$P=0.011$ & $P<0.001$ \\
Diastolic BP & $r=0.385$ & Glucose \\
$P=0.027$ & $r=0.365$ \\
& $P=0.016$ \\
\hline
\end{tabular}

BMI, body mass index; WHR, waist-to-hip ratio; BP, blood pressure. $r$, Pearson's correlation coefficient.

aLog-transformed values were used.

hypopituitary adults (31-33). In our study, older age, higher BMI, and presence of hypopituitarism significantly predicted higher IMT measurements in a logistic regression model. The eNOS4a/b polymorphism did not enter this model.

Endothelial dysfunction evaluated by FMD was also a feature of adult GHD $(7,8,10,11)$. Although FMD of brachial artery was lower in our patients, the difference did not reach statistical significance. No significant association was observed between FMD and study parameters. Relatively small sample size may be responsible for the lack of significant difference between FMD measurements. Methodological differences and skill of the operator have effects on FMD; however, in our study, all of the measurements were performed by one experienced investigator ( $\mathrm{H} \mathrm{O}$ ). Brachial artery FMD is a functional parameter of endothelium, therefore, is subject to dynamic changes (12). Carotid artery IMT is an anatomical parameter of subclinical atherosclerosis (25). Previous studies also indicated discordant FMD and IMT results in hypopituitary GH-deficient adults; a more atherogenic IMT while FMD was similar to controls or vice versa $(34,35)$. Recently, it is suggested that although IMT and FMD are used as surrogate markers of preclinical asymptomatic atherosclerosis, they reflect different and independent stages of early atherosclerotic process and are not predicted by each other $(36,37)$. Measurement of FMD has been reported to have less significance in comparison with IMT in individual cardiovascular risk prediction (38).

Polymorphism of eNOS gene may influence the functional activity of the enzyme and has modulating effects on atherogenesis. Previous studies indicated functional/phenotypic significance of eNOS $4 \mathrm{a} / \mathrm{b}$ polymorphism in various conditions and indirect effects on atherogenesis (39-42) In addition, Wang et al. (43) reported that this polymorphism could influence transcriptional activity of eNOS gene. Tsukada et al. (15) showed that plasma NO level of healthy subjects with the 'a' allele was significantly lower than in those without 'a' allele $(P<0.05)$.

Fatini et al. (44) showed that the $4 \mathrm{a}$ allele and the combined genotypes of 'a' allele with other eNOS gene polymorphisms were significantly associated with carotid atherosclerosis. Interestingly, in this study, a relatively high incidence of the $4 \mathrm{a}$ allele and combined genotype of 'a' allele with another polymorphism (T-786C) was observed in a subset of patients with no traditional risk factors for atherogenesis ( $n$ : 30). This observation has been confirmed by Ischihara et al. (18). In Ischihara's study, eNOS4a allele was an independent risk factor for myocardial infarction, particularly in patients lacking other conventional risk factors ( $n$ : 104). Therefore, deleterious effects of eNOS4a allele on atherosclerosis may occur independently from conventional risk factors.

Asakimori et al. (45) indicated that odds ratio for carotid plaque positivity was increased by a factor of 3.72 in the presence of 'a' allele of intron 4 polymorphism in non-diabetic hemodialysis patients. However, Lembo et al. (46) could not find any significant difference between the frequency of intron $4 \mathrm{a} / \mathrm{b}$ polymorphism in hypertensive patients with and without carotid plaques. A different phenotype - established atherosclerosis - was investigated in last two cited studies. We aimed to investigate early vascular manifestation of atherosclerosis in our study.

In our study, although eNOS4a/b polymorphism did not enter in logistic regression model to predict IMT and no significant difference was observed between FMD measurements in patients and controls carrying 'a' allele and b/b genotype, 'a' allele of eNOS in patients might offer more detrimental effects on early atherosclerotic changes compared with controls. Patients with 'a' allele had significantly higher IMT compared with controls carrying 'a' allele and b/b genotype. However, no significant difference with respect to IMT was observed between hypopituitary patients carrying 'a' allele and bb genotype. The small sample size of patients carrying 'a' allele ( $n: 11$ ) limited us to comment further. A larger number of patients would be needed to clearly identify the deleterious/protective effects and pathogenetic mechanisms of $4 \mathrm{a} / \mathrm{b}$ polymorphism on atherogenesis in GH-deficient situations.

The limitations of our study are relatively small sample size and its cross-sectional design. Although conventional replacement therapy was given to the hypopituitary group, we cannot entirely rule out the effects of under or over treatment of cortisol deficiency and hypogonadism on study parameters. In addition, NO plasma concentrations were not directly measured. Markers of oxidative stress and inflammation were not included in study parameters. Other eNOS gene polymorphisms associated with atherosclerotic vascular phenotypes in studies with a wide range of subject numbers ( $n$ : 36-879), such as $-786 \mathrm{~T} \rightarrow \mathrm{C}$ and 
Glu298 $\rightarrow$ Asp could not be investigated in our study (20, 44-47).

As a conclusion, this study confirms that GH-deficient hypopituitary patients on conventional replacement therapy other than $\mathrm{GH}$ have early atherosclerotic changes and a more atherogenic milieu. Although eNOS4a allele in patients seems to have a more detrimental effect compared with 'a' allele carrying controls on early atherosclerotic changes, our data are not sufficient to suggest that NOS4a/b polymorphism modifies the atherosclerotic process in GH-deficient situations.

Prospective studies with larger groups of patients and different polymorphisms of eNOS gene are needed to determine the pathogenetic link between eNOS gene polymorphism and atherogenesis in this special group of patients. Future studies are also needed to detect whether improving effects of $\mathrm{GH}$ replacement therapy on atherogenesis could be influenced by eNOS $4 a / b$ genotypes.

\section{Acknowledgements}

This work is supported by Research Fund of the Istanbul University (project no. 294/05012005). We have no conflict of interest to declare.

\section{References}

1 Rosen T \& Bengtsson BA. Premature mortality due to cardiovascular disease in hypopituitarism. Lancet 1990336 285-288.

2 Bates AS, Hoff WV, Jones PJ \& Clayton RN. The effect of hypopituitarism on life expectancy. Journal of Clinical Endocrinology and Metabolism 199681 1169-1172.

3 Bülow B, Hagmar L, Mikoczy Z, Nordström C-H \& Erfurth EM. Increased cerebrovascular mortality in patients with hypopituitarism. Clinical Endocrinology $1997 \mathbf{4 6}$ 75-81.

4 Tomlinson JW, Holden N, Hills RK, Wheatley K, Clayton RN, Bates AS, Sheppard MC, Steward PM \& West Midlands Prospective Hypopituitary Study Group. Association between premature mortality and hypopituitarism. Lancet $2001357425-431$.

5 Stavrou S \& Kleinberg DL. Diagnosis and management of GH deficiency in adults. Endocrinology and Metabolism Clinics of North America 200130 545-563.

6 Carroll PV, Christ ER, Bengtsson B-A, Carlsson L, Christiansen JS, Clemmonds D, Hintz R, Ho K, Laron Z, Sizonenko P, Sönksen PH, Tanaka T \& Thorner M. Growth hormone deficiency in adulthood and the effects of growth hormone replacement: a review. Journal of Clinical Endocrinology and Metabolism 199883 382-395.

7 Evans LM, Davies JS, Anderson RA, Ellis GR, Jackson SK, Lewis MJ, Frenneaux MP, Rees A \& Scanlon MF. The effect of GH replacement therapy on endothelial function and oxidative stress in adult growth hormone deficiency. European Journal of Endocrinology 2000142 254-262.

8 Abdu TA, Elhadd TA, Buch H, Bayton D, Neary R \& Clayton RN. Recombinant GH replacement in hypopituitary adults improves endothelial cell function and reduced calculated absolute and relative coronary risk. Clinical Endocrinology 2004 61 387-393.

9 Abs R, Feldt-Rasmussen U, Mattsson AF, Monson JP, Bengtsson BA, Goth MI, Wilton P \& Koltowska-Haggstrom M. Determinants of cardiovascular risk in 2589 hypopituitary GH-deficient adults - a KIMS database analysis. European Journal of Endocrinology 2006 155 79-90.

10 Abdu TA, Elhadd T, Pfeifer M \& Clayton RN. Endothelial dysfunction in endocrine disease. Trends in Endocrinology and Metabolism 200112 257-265.

11 Yki-Jarvinen H. Insulin resistance and endothelial dysfunction. Best Practice and Research. Clinical Endocrinology and Metabolism $200317411-430$.

12 Celermajer DS, Sorensen KE, Gooch WM, Spiegelhalter DJ, Miller OI, Sullivan JD, Lloyd JK \& Deanfield JE. Non-invasive detection of endothelial dysfunction in children and adults at risk of atherosclerosis. Lancet $1992 \mathbf{3 4 0} 1111-1115$.

13 Anderson TJ, Uehata A, Gerhard MD, Meredith IT, Knab S, Delagrange D, Lieberman EH, Ganz P, Creager MA, Yeung AC \& Selwyn AP. Close relation of endothelial function in the human coronary and peripheral circulations. Journal of the American College of Cardiology 199526 1235-1241.

14 Takase B, Harnabe A, Satomura K, Akima T, Uehata A, Matsui T, Ohsuzu F, Ishihara M \& Kurita A. Comparable prognostic value of vasodilator response to acetylcholine in brachial and coronary arteries for predicting long-term cardiovascular events in suspected coronary artery disease. Circulation Journal $2006 \mathbf{7 0}$ 49-56.

15 Tsukada T, Yokoyama K, Arai T, Takemoto F, Hara S, Yamada A, Kawaguchi Y, Hosoya T \& Igari J. Evidence of association of the ecNOS gene polymorphism with plasma NO metabolite levels in human. Biochemical and Biophysical Research Communications 1998 245 190-193.

16 Yoon Y, Song J, Hong SH \& Kim JQ. Plasma nitric oxide concentrations and nitric oxide synthase gene polymorphism in coronary artery disease. Clinical Chemistry 200046 1626-1630.

17 Cine N, Hatemi AC \& Erginel-Unaltuna N. Association of a polymorhism of the ecNOS gene with myocardial infarction in a subgroup of Turkish MI patients. Clinical Genetics 200261 66-67.

18 Ichihara S, Yamada Y, Fujimura T, Nakashima N \& Yokota M. Association of a polymorphism of the endothelial constitutive nitric oxide synthase gene with myocardial infarction in the Japanese population. American Journal of Cardiology 199818 83-86.

19 Shoji M, Tsuyata S, Saito R, Takamoto H \& Yasujimi M. Positive association of endothelial nitric oxide synthase gene polymorphism with hypertension. Life Sciences 200066 2557-2562.

20 Miyamoto Y, Saito Y, Kajiyama N, Yoshimura M, Shimasaki Y, Nakayama M, Kamitani S, Harada M, Ishikawa M, Kuwahara K, Ogawa E, Hamanaka I, Takahashi N, Kaneshige T, Teraoka H, Akamizu T, Azuma N, Yoshimasa Y, Yoshimasa T, Itoh H, Masuda I, Yasue $\mathrm{H}$ \& Nakao K. Endothelial nitric oxide synthase gene is positively associated with essential hypertension. Hypertension 1998 32 3-8.

21 Hibi K, Ishigami T, Tamura K, Mizishima S, Nyui N, Fujita T, Ochiai H, Kosuge M, Watanabe Y, Yoshii Y, Kihara M, Kihara M, Kimura K, Ishii M \& Umemura S. Endothelial nitric oxide synthase gene polymorphism and acute myocardial infarction. Hypertension $199832521-526$.

22 Granath B, Taylor RR, van Bockxmeer FM \& Mamotte CDS. Lack of evidence for association between endothelial nitric oxide synthase gene polymorphisms and coronary artery disease in the Australian Caucasian population. Journal of Cardiovascular Risk 20018 235-241.

23 Böger RH, Skamira C, Bode-Böger SM, Brabant G, Von Zur Muhlen A \& Frölich JC. Nitric oxide may mediate the haemodynamic effects of recombinant human growth hormone in patients with acquired growth hormone deficiency. Journal of Clinical Investigation 199698 2706-2713.

24 Tsukahara H, Gordienko DV, Tonshoff B, Gelato M \& Goligorsky MS. Direct demonstration of insulin-like growth factor-I-induced nitric oxide production by endothelial cells. Kidney International 199445 598-604.

25 Crouse JR III, Craven TE, Hagaman AP \& Bond MG. Associations of coronary disease with segment specific intimal-medial thickening of the extracranial carotid artery. Circulation $1995921141-1147$. 
26 Grobbe DE \& Bots ML. Carotid artery intima-media thickness as an indicator of generalized atherosclerosis. Journal of Internal Medicine $1994235431-433$.

27 Hartman ML, Crowe BJ, Biler BMK, Ho KKY, Clemmons D \& Chipman JJ. Which patients do not require a GH stimulation test for the dignosis of adult GH deficiency? Journal of Clinical Endocrinology and Metabolism 200287 477-485.

28 Ghigo E, Masel B, Aimaretti G, Leon-Carrion J, Casanueva FF, Dominguez-Morales MR, Elovic E, Perrone K, Stalla G, Thompson C \& Urban R. Consensus guidelines on screening for hypopituitarism following traumatic brain injury. Brain Injury $200519711-724$.

29 Leong KS, Walker AB, Martin I, Wile D, Wilding J \& MacFarlane IA. An audit of 500 subcutaneous glucagon stimulation tests to assess growth hormone and ACTH secretion in patients with hypothalamic pituitary disease. Clinical Endocrinology 2001 54 463-468.

30 Ozbey N, Telci A, Cakatay U, Yurci A \& Molvalilar S. Determination of oxidative protein and lipid damage in adult hypopituitary patients with GH deficiency. Journal of Endocrinological Investigation 200326 1001-1007.

31 Markussis V, Besyah SA, Fischer C, Sharp P, Nicolaides AN \& Johnston DG. Detection of premature atherosclerosis by high resolution ultrasonography in symptom free hypopituitary adults. Lancet $19923401188-1192$.

32 Capaldo B, Patti L, Oliviero U, Longobardi S, Pardo F, Vitale F, Fazio S, Di Rella F, Biondi B, Lombardi G \& Sacca L. Increased arterial intima media thickness in childhood onset growth hormone deficiency. Journal of Clinical Endocrinology and Metabolism 199782 1373-1381.

33 Markussis V, Beshyah SA, Fischer C, Parker K, Nicolaides AN \& Johnston DG. Abnormal carotid artery wall dynamics in symptom free hypopituitary adults. European Journal of Endocrinology 1997 136 157-164.

34 Pfeifer M, Verhovec R, Zizec B, Prezelj J, Poredos P \& Clayton RN. Growth hormone treatment reverses early atherosclerotic changes in GH-deficient adults. Journal of Clinical Endocrinology and Metabolism $1999 \mathbf{8 4} 453-457$.

35 Elhadd TA, Abdu TA, Oxtoby J, Kennedy G, McLaren M, Neary R, Belch JJF \& Clayton RN. Biochemical and biophysical markers of endothelial dysfunction in adults with hypopituitarism and severe GH deficiency. Journal of Clinical Endocrinology and Metabolism $2001864223-4232$.

36 Yan RT, Anderson TJ, Charbonneau F, Title L, Verma S \& Lonn E. Relationship between carotid artery intima-media thickness and brachial artery flow-mediated dilation in middle-aged healthy men. Journal of the American College of Cardiology 200545 1980-1986.
37 Irace C, Fiashi E, Cortese C \& Gnasso A. Flow-mediated vasodilation of the brachial artery and intima-media thickness of carotid artery in never-treated subjects. International Angiology $200625274-279$.

38 Ter Avest E, Stalenhoef AF \& de Graaf J. What is the role of noninvasive measurements of atherosclerosis in individual cardiovascular risk prediction? Clinical Science 2007112 507-516.

39 Asanuma K, Yokoyama K, Tsukada T, Takemoto F, Hara S, Yamada A \& Tomino Y. An intron 4 gene polymorphism in endothelial cell nitric oxide synthase might modulate lipid metabolism in nondiabetic patients on hemodialysis. Nephron 2001 88 39-43.

40 Basaran O, Atac FB, Karakayali F, Aliosmanoglu I, Yagmurdur MC, Ozdemir FN \& Haberal M. Endothelial nitric oxide synthase gene intron 4 (VNTR) polymorphism and vascular access graft thrombosis. Journal of Investigative Surgery 200720 49-53.

41 Dursun H, Noyan A, Maytar S, Buyukcelik M, Soran M, Cengiz N, Seydaoglu G, Attila G, Bayazit AK \& Anarat A. Endothelial nitric oxide synthase gene intron $4 \mathrm{a} / \mathrm{b}$ VNTR polymorphism in children with APSGN. Pediatric Nephrology 2006 21 1661-1665.

42 Droma Y, Hanaoka M, Ota M, Katsuyama Y, Kouzumi T, Fujimoto K, Kobayashi T \& Kubo K. Positive association of the endothelial nitric oxide synthase gene polymorphisms with highaltitude pulmonary edema. Circulation 2002106 826-830.

43 Wang J, Dudley D \& Wang XL. Haplotype-specific effects on endothelial NO synthase promoter efficiency. Modifiable by cigarette smoking. Arteriosclerosis, Thrombosis, and Vascular Biology 200222 e1-e4.

44 Fatini C, Sofi F, Gensini F, Sticchi E, Lari B, Pratesi C, Gensini GF \& Abbate R. Influence of eNOS gene polymorphisms on carotid atherosclerosis. European Journal of Vascular and Endovascular Surgery 200427 540-544.

45 Asakimori Y, Yorioka N, Tanaka J \& Kohno N. Effect of polymorphism of the endothelial nitric oxide synthase and apolipoprotein E genes on carotid atherosclerosis in hemodialysis patients. American Journal of Kidney Diseases $200341822-832$.

46 Lembo G, De Luca N, Battagli C, Iovino G, Aretini A, Musicco M, Frati G, Pompeo F, Vecchione C \& Trimarco B. A common variant of endothelial nitric oxide synthase (Glu298Asp) is an independent risk factor for carotid atherosclerosis. Stroke 2001 32 735-740.

47 Zineh I, Beitelshees AL \& Haller MJ. NOS3 polymorphism are associated with arterial stiffness in children with type 1 diabetes. Diabetes Care 200730 689-693.

Received 5 February 2008

Accepted 6 February 2008 